\title{
SOCIAL GROUP AS REFLECTION OF SELF: AUTISM SPECTRUM DISORDER IN THE MIRROR - CONNECTING THE PUZZLE OF THE SELF
}

\begin{abstract}
Feingold Enav Tamar, Social Group as Reflection of Self: Autism Spectrum Disorder in the Mirror - Connecting the Puzzle of the Self [Grupa społeczna jako obraz własnej tożsamości: spektrum autyzmu w zwierciadle - układanka tożsamości]. Studia Edukacyjne nr 51, 2018, Poznań 2018, pp. 503-513. Adam Mickiewicz University Press. ISSN 1233-6688. DOI: 10.14746/se.2018.51.31
\end{abstract}

From a social-cognitive perspective, how we come to see ourselves is partially a reflection of how others see us, hence the idea of the "looking glass self". Autism is a neuro-developmental disorder, characterized by difficulties in social-emotional reciprocity, in nonverbal communicative behaviors used for social interaction, and in the development, preservation and understanding of social interactions. As social interaction is the critical mechanism of development, people diagnosed with Autism are likely to have difficulties in developing their ,self'. This article suggests a CBT oriented peer group for individuals with autism, in order to help connecting the ,self' puzzle.

Key words: self, autism, Cognitive-Behavioral Therapy, group

\section{The Looking glass Self}

Charles Cooley ${ }^{1}$ launched the theory of "mirror self", that describes the ways in which other people's opinions about or reactions to self, influence a person's formulation of self-concept. Joseph ${ }^{2}$ stated that the mirror is a primary symbol of psyche, a best possible representation of an otherwise unknown (and unknowable) reality. According to Cooley, ${ }^{3}$ the self is socially constructed and that "reflected appraisals" form the core of self-understanding. At all times we look and analyze the images sent by those around us,

${ }^{1}$ C.H. Cooley, Human Nature and the Social Order, New York 1902.

2 S.M. Joseph, Presence and Absence through the Mirror of Transference: A Model of the Transcendent Function, Journal of Analytical Psychology, 1997, 42, 1, p. 139-156.

${ }^{3}$ Ibidem. 
representing mirrors in which we observe ourselves. Mirrors differ from each other and offer different images. Constant adaptation to these images triggers certain behaviors, certain reactions and types of action. ${ }^{4}$

G.H. Mead ${ }^{5}$ deems the 'self' as something that has to be developed. While interacting with others, individuals monitor others' reactions to the self and use that feedback to formulate and update their self-concept, both in terms of who they are and "how good" they are. ${ }^{6}$ The 'self' is "not initially present at birth, and is something which has to be developed; self arises through the process of social experience and activity, and as a result of the relationship to that process as a whole and to the individuals within that process." ${ }^{7}$ The self can be seen as an organizer for one's social world, and provide him the conceptual means to distinguish himself from others and establish a unique personal identity. ${ }^{8}$

Thus, social interaction is the critical mechanism of development, as the self begins purely as a reflection of the other, the looking-glass self. ${ }^{9}$ Fivush \& Waters ${ }^{10}$ further argue that if all that exists is a presentational self, and there is no internalization of what one learns or understands about the self from these momentary interactions, then there is no mechanism for growth or development.

What then is the ability to form one's self, when there is an inherent deficiency in one's ability in the development, preservation and understanding of social interactions?

\section{Autistic Spectrum Disorder (ASD)}

The word Autism is derived from the Greek word "autos", meaning "self". The term describes a condition in which a person withdraws from so-

${ }^{4}$ I. Rotaru, L. Nitulescu, E. Balas, The Self in the Communication Process, Procedia - Social and Behavioral Sciences, 2010, 5, p. 331-333.

${ }^{5}$ G.H. Mead, Mind, Self, and Society: From the Standpoint of a Social Behaviorist, Chicago 1962.

${ }^{6}$ B.B. Brown et al., Sharing Information about Peer Relations: Parent and Adolescent Opinions and Behaviors in Hmong and African American Families, New Directions for Child and Adolescent Development, 2007, 116, p. 67-82.

${ }_{7}^{7}$ G.H. Mead, Mind, Self, and Society, p. 135.

8 W. James, Psychology: The Briefer Course, New York 1961; W. Damon, D. Hart, Self-Understanding in Childhood and Adolescence, CUP Archive, 1991.

9 R. Fivush, T.E.A. Waters, Re-Presenting the Presentational Self. Commentary on Komatsu, Commentary Human Development, 2010, 53, p. 229-234.

${ }^{10}$ Ibidem. 
cial interaction. It can be viewed as an infirmity of the development of an individual's 'self'. ${ }^{11}$

Autism is a neuro-developmental disorder, affecting approximately $1 \%$ of the population, ${ }^{12}$ that is characterized by difficulties in social-emotional reciprocity, in nonverbal communicative behaviors used for social interaction, and in the development, preservation and understanding of social interactions. ${ }^{13}$ Moreover, autism is accompanied by difficulty with changes, sensory sensitivity, reduced fields of interest, and repeated motor movements. This is a hierarchy of lacks positioned on a spectrum. Every disorder can be expressed differently in each child, and therefore the variety of unusual behaviors is very great. Being a heterogeneous condition: no two children or adults with autism have exactly the same profile, but difficulties fall into core domains that are reliably measured and usually consistent across time, even though specific behaviors may change with development. ${ }^{14}$ The challenges individuals with ASD experience with awareness and emotional recognition, leads to debility of self. ${ }^{15}$

Two subgroups that are often grouped together in research designs and clinical service provision are Asperger syndrome (AS) and high functioning autism (HFA). Prior to the latest edition of the Diagnostic and Statistical Manual of Mental Disorders ${ }^{16}$ (predominantly used in the United States), AS was a discrete diagnosis, separated primarily due to the core feature of typical language acquisition. HFA is a widely used clinical diagnosis to identify individuals on the autistic spectrum, who had a history of language delay but do not have the associated difficulties of an intellectual impairment. ${ }^{17}$ AS is still applicable according to the World Health Organization International Classification of Diseases (ICD-10) ${ }^{18}$ (used in other countries throughout the world).

11 C.K. Duff, J.J. Flattery Jr., Developing Mirror Self Awareness in Students with Autism Spectrum Disorder, Journal of Autism \& Developmental Disorders, 2014, 44, p. 1027-1038.

12 M.C. Lai, M. V. Lombardo, S. Baron-Cohen, Autism, The Lancet, 2014, 383, p. 896-910.

13 American Psychiatric Association, Diagnostic and Statistical Manual of Mental Disorders (DSM-5®) American Psychiatric Pub, 2013.

14 C. Lord, E.H. Cook, B.L. Leventhal, Autism: The Science of Mental Health, Ed. S. Hyman, New York - London, 2013.

15 C.K. Duff, J.J. Flattery Jr., Developing Mirror Self Awareness.

16 American Psychiatric Association.

17 C.B. Montgomery et al., Do Adults with High Functioning Autism or Asperger Syndrome Differ in Empathy and Emotion Recognition? Journal of Autism and Developmental Disorders, 2016, 46, 6, p. 1931-1940.

18 World Health Organization, The ICD-10 Classification of Mental and Behavioural Disorders: Diagnostic Criteria for Research, World Health Organization, Geneva 1994. 
Despite high level of intelligence, both conditions present with varying degrees of difficulty in social communication alongside the presence of unusually narrow interests, resistance to change, and highly repetitive behaviors. ${ }^{19}$

This study will discuss adolescents and adults diagnosed with HFA and AS.

Deficits in social communication may cause noticeable impairments. Difficulty initiating social interactions and clear examples of atypical or unsuccessful response of social overtures of others, individual diagnosed with ASD may appear to have decreased interest in social interaction.

\section{The challenges of adolescents and adults diagnosed with ASD confronting the "Mirror"}

To assess the total concept of self, it is important to measure one's understanding of both one's own perceptions and those of others, as well as different social and psychological contexts from which others' perceptions are coming. ${ }^{20}$

Since the development of 'Self' is contingent upon the construct of 'Oth$\mathrm{er}^{\prime}{ }^{21}$ people with autism are at a distinct disadvantage for self-development, as their social withdrawal impedes the developmental experience of reasonably considering 'Other' in their self-awareness and recognition. This may lead to a negatively skewed view of 'Self' in people diagnosed with ASD. ${ }^{22}$

Formulating a self-concept requires the ability to imagine one's appearance to the other, to imagine their judgment of that appearance and to experience a resulting feeling. ${ }^{23}$ This process begins at early age, through imitation. ${ }^{24}$ However, following these elements by individuals diagnosed with HFA or AS entails difficulties due to their inherent deficits. Disorders of self in autism have usually been addressed by the major cognitive theories of autism, particularly the impaired 'theory of mind' hypothesis, 'central coherence' and 'executive functioning'.

"Theory of mind" (ToM) is the ability to attribute mental states, such as beliefs, desires, and intentions, to self and others to explain and predict the be-

\footnotetext{
${ }^{19}$ F.R. Volkmar, J.C. Partland, From Kanner to DSM-5: Autism as an Evolving Diagnostic Concept, Annual Review of Clinical Psychology, 2014, 10, p. 193-212.

${ }^{20}$ D. Williams, Theory of Own Mind in Autism: Evidence of a Specific Deficit in Self-Awareness? Autism, 2010, 14, 5, p. 474-494.

${ }^{21}$ C.H. Cooley, Human nature; G.H. Mead, Mind, self and society.

22 C.K. Duff, J.J. Flattery Jr., Developing Mirror Self Awareness.

${ }^{23}$ C.H. Cooley, Human nature.

${ }^{24}$ G.H. Mead, Mind, self and society.
} 
havior of others, based on their mental states. ${ }^{25}$ This ability involves a search for prior knowledge about the behavior, agent or context. Behaviorally, ToM involves attempts to detect subtle signs in the agent's external behavior by tracking gaze and body orientation, as well as reading facial and body expression. According to Baron-Cohen, Tager-Flusberg \& Cohen, ${ }^{26}$ individuals with autism have difficulty in identifying and conceptualizing the thoughts and feelings of other people and themselves, and thus fail to attribute (false) beliefs to others. This challenge in being able to walk in another person's shoes, also called mind reading, ${ }^{27}$ at times, leads to the conclusion that people with ASD lack empathy for others. "The inter-personal and inner world of emotions appears to be uncharted territory for people with AS". ${ }^{28}$ Studies that examined theory of mind functioning of adults with HFA and AS are limited..$^{29}$ According to Spek et al., ${ }^{30}$ most adults with HFA or AS show difficulties in 'advanced theory of mind', which involves interpreting complex social situations, based on subtle information. Deficit in ToM may entail hardship in choosing an appropriate and adaptive social behavior and regulating one's emotional response to a given situation. Difficulties in perceiving emotional states or reactions, considering plausible causal factors, understanding the interests of others and previous knowledge others hold, may cause misconceptions about others and ineffective social communication or social isolation, all of which mirrors negative self-image. ${ }^{31}$

"Central Coherence" is a system whose job is to integrate sources of information to establish meaning. Frith ${ }^{32}$ suggested this ability is weak in individuals with autism, with the result that they attend only to small bits rather than to large, globally coherent patterns of information. Achieving coherence involves central thought processes. According to Jolliffe and Baron-Cohen, ${ }^{33}$ individuals with AS have a tendency to focus on details and not to integrate information co-

${ }^{25}$ D. Premack, G. Woodruff, Does the Chimpanzee Have a Theory of Mind? Behavioral and Brain Sciences, 1978, 1, 4, p. 515-526.

${ }^{26}$ S. Baron-Cohen, H. Tager-Flusberg, D.J. Cohen (Ed.), Understanding Other Minds: Perspectives from Autism, New York 1994.

27 S. Baron-Cohen, Mindblindness. An Essay on Autism and Theory of Mind, Cambridge 1995.

${ }_{28}^{28}$ T. Attwood, Cognitive Behavior Therapy for Children and Adults with Asperger's Syndrome, Behavior Change, 2004, 21, 3, p. 149.

29 A.A. Spek, E.M. Scholte, I.A. Van Berckelaer-Onnes, Theory of Mind in Adults with HFA and Asperger Syndrome, Journal of Autism and Developmental Disorders, 2010, 40, 3, p. 280-289.

${ }^{30}$ Ibidem.

${ }^{31}$ A.X. Huang et al., Understanding the Self in Individuals with Autism Spectrum Disorders (ASD): A Review of Literature, Frontiers in Psychology, 2017, 8.

${ }^{32}$ U. Frith, Autism - Are We Any Closer to Explaining the Enigma? Psychologist, 2014, 27, 10, p. $744-745$.

${ }_{33}$ T. Jolliffe, S. Baron-Cohen, Linguistic Processing in High-Functioning Adults with Autism or Asperger's Syndrome. Is Global Coherence Impaired? Psychological Medicine, 2000, 30, 5, p. 11691187. 
herently. Information processing in real life usually involves the interpretation of individual stimuli in terms of overall context. A decreased ability to interpret information in context disrupts communication ability. ${ }^{34}$

"Executive Functions" (EF) is an umbrella term for functions such as planning, working memory, impulse control inhibition and mental flexibility, as well as for the initiation and monitoring of action. According to Hill, ${ }^{35}$ school aged and adult autistic individuals of all ability ranges are impaired in the executive function of planning and of mental flexibility. "Impaired executive function can also affect the cognitive control of emotions. Clinical experience indicates there is a tendency to react to emotional cues without cognitive reflection. ${ }^{\prime 36}$ Berna et al. ${ }^{37}$ propose that executive dysfunction may also contribute to self-disorder through its negative impact on ToM capacities.

When one considers the difficulties of individuals with HFA or AS with regard to social reasoning, empathy, verbal communication, profile of cognitive skills and sensory perception, while "looking in the mirrors", they are clearly prone to develop maladaptive cognitive structures or schemas regarding their Self. "Self-awareness and knowledge is not something that can simply be taught through direct instruction. Instead, students acquire this knowledge by interacting with their environment." ${ }^{\prime 38}$

\section{Connecting the puzzle of the 'Self': CBT oriented groups for individuals with HFA or AS}

Due to impaired social interaction, HFA and AS are at increased risk for peer rejection, social isolation, mood problems and anxiety. Thus, there is a strong need of interventions aiming at negotiating maladaptive cognition structures through improving reciprocal social interaction skills, especially with peers. ${ }^{39}$ A defining feature of cognitive-behavioral therapy (CBT) is the proposition that symptoms and dysfunctional behaviors are often cognitively mediated, hence, improvement can be produced by modifying dysfunctional thinking and be-

34 Ibidem.

35 E.L. Hill, Executive Dysfunction in Autism, Trends in Cognitive Sciences, 2004, 8, 1, p. 26-32.

36 T. Attwood, Cognitive Behavior Therapy for Children, p. 149.

37 F. Berna et al., Self-Disorders in Individuals with Autistic Traits: Contribution of Reduced Autobiographical Reasoning Capacities, Journal of Autism and Developmental Disorders, 2016, 46, 8, p. 2587-2598.

38 C.K. Duff, J.J. Flattery Jr., Developing Mirror Self Awareness, p. 1027.

39 C.M. Freitag et al., Group-based Cognitive Behavioural Psychotherapy for Children and Adolescents with ASD: The Randomized, Multicentre, Controlled SOSTA - Net Trial, Journal of Child Psychology and Psychiatry, 2015, 57, 5, p. 596-605. 
liefs. ${ }^{40}$ Most of the therapeutic interventions, devised within Beck' $\mathrm{s}^{41}$ cognitive therapy, aims to target maladaptive cognitive structures, or schemas, which contain core beliefs about self, world/others, and the future, and determine automatic thoughts, images, and memories in specific situations. ${ }^{42}$

A fundamental principle of CBT is that it addresses not only the behavioral manifestations of problems, but also seeks to understand and remit the underlying cognitions that lead to those behaviors. The majority of studies using CBT for individuals with ASD have been conducted predominantly in private patient settings. ${ }^{43}$ However, in research literature, groups for youth and adolescents showed an amount of success in the area of social skills. ${ }^{44}$ Freitag et al. ${ }^{45}$ researched group-based CBT for children and adolescents with ASD. They concluded the low intensity ASD specific group-based therapy, have shown efficacy. These groups provide opportunities for learning and practicing diverse progressive social skills, for those individuals whom mostly in such need, but due to their inherent inabilities, lack. Participating in a peer group is of highly importance. The group consist of therapeutic factors such as inspiring hope, developing socialization techniques, imitation, inter-personal learning, group cohesion, catharsis and providing information. ${ }^{46}$ The peer groups of individuals with HFA or AS may be of same age people, all diagnosed with HFA or AS; or same age, typically developed. Both peer groups are significant "mirrors" for individuals with ASD in developing their 'Self'. Being part of a peer group may bestow the individual with the opportunity for intensive observation in mirrors, thus, a means to be aware of one's self as an integrated whole, including his patterns and behaviors, ${ }^{47} \mathrm{such}$ integrated awareness is imperative in the process of self-development. CBT oriented peer group provides the conditions for working on the fundamental

${ }^{40}$ K.S. Dobson, D.J.A. Dozois, Handbook of Cognitive-Behavioral Therapies, Third Edition, Keith S. Dobson ed., New York 2009.

41 A.T. Beck, Thinking and Depression, Archives of General Psychiatry, 1963, 9, p. 324-333.

${ }^{42}$ N. Kazantzis et al., The Processes of Cognitive Behavioral Therapy: A Review of Meta-Analyses, Cognitive Therapy and Research, 2018, 42, 4, p. 349-357.

${ }^{43}$ E. Rotheram Fuller, L. MacMullen, Cognitive behavioral Therapy for Children with Autism Spectrum Disorders, Psychology in the Schools, 2011, 48, 3, p. 263-271.

44 J. Manjiviona, M. Prior, Comparison of Asperger Syndrome and High-Functioning Autistic Children on a Test of Motor Impairment, Journal of Autism and Developmental Disorders, 1995, 25, 1, p. 23-39; G.B. Mesibov, Social Skills Training with Verbal Autistic Adolescents and Adults: A Program Model, Journal of Autism and Developmental Disorders, 1984, 14, 4, p. 395; S. Ozonoff, J. Miller, Teaching Theory of Mind: A New Approach to Social Skills Training for Individuals with Autism, Journal of Autism and Developmental Disorders, 1995, 25, 4, p. 415-433; T.I. Williams, A Social Skills Group for Autistic Children, Journal of Autism and Developmental Disorders, 1989, 19, 1, p. 143-155.

${ }^{45}$ C.M. Freitag et al., Group based Cognitive Behavioral Psychotherapy.

46 I.D. Yalom, The Theory and Practice of Group Psychotherapy, 4th ed., New York 1995.

47 Y. Ziv, Group Journey, Israel 2011. 
elements required for the development of one's 'Self'. It has been associated with improved social communication, social motivation and social awareness. ${ }^{48}$ The number of participants in the peer group for individuals with HFA should be small, in order to allow personal attention, and it is of most importance for the individual with HFA or AS to acknowledge his diagnosis and his need for assistance. ${ }^{49}$ Sometimes being part of a peer group of HFA or AS may present very hard reflections to endure. Engaging in reciprocal relations with the group members, in a safe surrounding allows catharsis to arise naturally, through which distorted conceptualizations and dysfunctional beliefs revealed. Followed by psychoeducation, group discussion and Socratic questioning, one may gain insight into his maladaptive cognitions, be aware of other cognitions in the group, triggering a more flexible thinking.

The group members form a circle of mirrors for the individual in it, differ from each other and offer different images. Participating in a peer group for individuals with HFA or AS, provides the individual with many opportunities to practice situations requiring ToM abilities in-vivo. Being able to explore one's cognitive inferences and emotional reactions within the group, provides him on one hand, the conceptual means to distinguish himself from others, and on the other hand, promotes achieving coherence. There are many models to forward CBT elements, usually in a very coordinated logical manner, which helps individuals with HFA or AS understand. One of the models known is EFRAT model, which is the Hebrew abbreviations for Event, Interpretation, Emotion and Response. Accordingly, how we interpret or think about a situation determines how we feel about it, which then determines how we will react. This understanding, that we all interpret life events in different ways, based on past life experiences, allows the group' participants share their different interpretations and thus, practice the understanding that each has his own different thoughts (ToM). Moreover, it is an opportunity to correct distorted conceptualizations and dysfunctional beliefs. As a result of one's thoughts about a situation, he experiences emotions. This understanding allows the group members to acknowledge and experience a wide range of emotions. The main goal is to understand "why we have emotions, how such emotions are used and misused and to identify different levels of expression." ${ }^{50}$ Raising emotional understanding, promotes ToM and empathy skills, known to be impaired in this population. Consequently, following different interpretations (thoughts) and emotions, individuals react, once again, in dif-

48 J.J. Wood et al., Cognitive Behavioral Therapy for Anxiety in Children with Autism Spectrum Disorders: A Randomized, Controlled Trial, Journal of Child Psychology and Psychiatry, 2009, 50, 3, p. 224-234.

49 T. Attwood, Asperger Syndrome: A Guide for Parents and Professionals, London 1998.

50 T. Attwood, Cognitive Behavior Therapy for Children, p. 149. 
ferent ways. The group mirrors the consequences and effects of the individu$\mathrm{al}^{\prime}$ 's behavior, and may offer various tools and techniques for emotional and executive functions regulation.

Most research reviews focuses on specific targets interventions, such as improving specific cognitive skills or emotion recognition, self-regulation and social interaction. ${ }^{51}$ To the best of my knowledge, no research has focused on the influence of group intervention regarding the development of an integrated developed 'Self' in adolescents and adults diagnosed with HFA or AS. Connecting the puzzle of the 'Self' by allowing this population experience social interaction, known to be a critical mechanism for the development of 'self', through cognitive-behavioral therapy oriented peer group, may show great outcomes. Future research is recommended to evaluate its efficiency in the formulation of one's self-concept.

\section{BIBLIOGRAPHY}

American Psychiatric Association, Diagnostic and Statistical Manual of Mental Disorders (DSM-5®) American Psychiatric Pub, 2013.

Attwood T., Asperger Syndrome: A Guide for Parents and Professionals, Jessica Kingsley Publishers Ltd., London 1998.

Attwood T., Cognitive Behavior Therapy for Children and Adults with Asperger's Syndrome, Behavior Change, 2004, 21, 3.

Baron-Cohen S., Mindblindness. An essay on autism and theory of mind, MIT Press, Cambridge 1995.

Baron-Cohen S., Tager-Flusberg H., Cohen D.J. (Eds.), Understanding other minds: Perspectives from autism, University Press, New York - Oxford 1994.

Beck A.T., Thinking and depression, Archives of General Psychiatry, 1963, 9.

Berna F., Göritz A.S., Schröder J., Coutelle R., Danion J.M., Cuervo-Lombard C.V., Moritz S., Self-Disorders in Individuals with Autistic Traits: Contribution of Reduced Autobiographical Reasoning Capacities, Journal of Autism and Developmental Disorders, 2016, 46, 8.

Bradford Brown B., Bakken J.P., Nguyen J., Von Kank H.G., Sharing information about peer relations: Parent and adolescent opinion and behaviors in Hmong and African American families, New Directions Child Adolescent Development, 2007, 116.

Brown B.B. et al., Sharing Information about Peer Relations: Parent and Adolescent Opinions and Behaviors in Hmong and African American Families, New Directions for Child and Adolescent Development, 2007, 116.

Cooley C.H., Human nature and the social order, Charles Scribner's Sons, New York 1902.

Damon W., Hart D., Self-understanding in childhood and adolescence, Cambridge University Press, Cambridge 1988.

Dobson K.S., Dozois D.J.A., Historical and philosophical bases of the cognitive behavioral therapies, [in:] Handbook of cognitive behavioral therapies, $3^{\text {rd }}$ ed., Ed. K.S. Dobson, Guilford Press, New York 2009.

${ }^{51}$ C.M. Freitag et al., Group based Cognitive Behavioral Psychotherapy. 
DSM-5, The Diagnostical and Statistical Manual of Mental Disorders, $5^{\text {th }}$ ed., American Psychiatric Association, 2013.

Duff C.K., Flattery Jr. J.J., Developing Mirror Self Awareness in Students with Autism Spectrum Disorder, Journal of Autism and Developmental Disorders, 2014, 44.

Fivush R., Waters T.E.A., Re-Presenting the Presentational Self. Commentary on Komatsu, Commentary Human Development, 2010, 53.

Freitag C.M., Jensen K., Elsuni L., Sachse M., Herpertz-Dahlmann B., Schulte-Rüther M., Hänig S., Group based Cognitive Behavioral Psychotherapy for Children and Adolescents with ASD: The Randomized, Multicentre, Controlled SOSTA - Net Trial, Journal of Child Psychology and Psychiatry, 2016, 57, 5.

Frith U., Autism: Explaining the enigma, Blackwell, Oxford 1989.

Hill E.L., Executive Dysfunction in Autism, Trends in Cognitive Sciences, 2004, 8, 1.

Huang A.X., Hughes T.L., Sutton L.R., Lawrence M., Chen X., Ji Z., Zeleke W., Understanding the Self in Individuals with Autism Spectrum Disorders (ASD): A Review of Literature, Frontiers in Psychology, 2017, 8.

James W., Psychology: The briefer course, Harper \& Row, New York 1961 (Originally published 1892).

Joliffe T., Baron-Cohen S., Linguistic processing in high-functioning adults with autism or Asperger's Syndrom. Is global coherence impaired? Psychological Medicine, 2000, 30, 5.

Joseph S., Presence and absence through the mirror of transference: A model of the transcendent function, Journal of Analytical Psychology, 1997, 42.

Kazantzis N., Luong H.K., Usatoff A.S., Impala T., Yew R.Y., Hofmann S.G., The Processes of Cognitive Behavioral Therapy: A Review of Meta-Analyses, Cognitive Therapy and Research, 2018, 42, 4.

Lai M.C., Lombardo M.V., Baron-Cohen C., Autism, The Lancet, 2014, 383.

Lord C., Cook E.H., Leventhal B.L., Autism: The Science of Mental Health, Ed. S. Hyman, Routledge, New York - London 2001.

Marriage K., Miles T., Stokes D., Davey M., Comparison of Asperger's Syndrome and High-Functioning Autistic children on a test of motor impairment, Journal of Autism and Developmental Disorders, 1995, 25.

Mead G.H., Mind, self and society: from the standpoint of a social behaviorist, (Edited with introduction by Charles W. Morris), The University of Chicago Press, Chicago, IL - London 1962.

Mesibov G.B., Social skills training with verbal autistic adolescents and adults: A program model, Journal of Autism and Developmental Disorders, 1984, 14, 4.

Montgomery C.B., Allison C., Lai M.C., Cassidy S., Langdon P.E., Baron-Cohen S., Do Adults with High Functioning Autism or Asperger Syndrome Differ in Empathy and Emotion Recognition? Journal of Autism and Developmental Disorders, 2016, 46, 6.

Ozonoff S., Miller J., Teaching theory of mind: A new approach to social skills training for individuals with autism, Journal of Autism and Developmental Disorders, 1995, 25.

Premack D., Woodruff G., Does The Chimpanzee have a "Theory of Mind"? Behavioral and Brain Sciences, 1978, 4.

Rotaru I., Nitulescu L., Balas E., The self in the communication process, Procedia Social and Behavioral Sciences, 2010, 5.

Rotheram Fuller E., MacMullen L., Cognitive behavioral Therapy for Children with Autism Spectrum Disorders, Psychology in the Schools, 2011, 48, 3.

Spek A.A., Scholte E.M., Van Berckelaer-Onnes I.A., Theory of Mind in Adults with HFA and Asperger Syndrome, Journal of Autism Developmental Disorders, 2010, 40, 3. 
Volkmar F.R., Partland J.C., From Kanner to DSM-5: Autism as an evolving diagnostic concept, Annual Review of Clinical Psychology, 2014, 10.

Wang Q., Ross M., Culture and memory, [in:] Handbook of cultural psychology, Eds. S. Kitayama, D. Cohen, Guilford, New York 2007.

Williams D., Theory of Own Mind in Autism: Evidence of a Specific Deficit in Self-Awareness? Autism, 2010, 14, 5.

Williams T.A., Social skills group for autistic children, Journal of Autism and Developmental Disorders, 1989, 19, 1.

Wood J., Drahota A., Sze K., Har K., Chiu A., Langer D., Cognitive behavioral therapy for anxiety in children with autism spectrum disorders: A randomized, controlled trial, Journal of Child Psychology \& Psychiatry, 2009, 50, 3.

World Health Organization (WHO), The ICD-10 classification of mental and behavioral disorders. Clinical descriptions and guidelines, WHO, Geneva 1994.

Yalom I.D., The Theory and Practice of Group Psychotherapy, $4^{\text {th }}$ ed., Basic Books, New York 1995.

Ziv Y., Group Journey, Gala Kedem Print LTD, Israel 2011. 